\title{
Temporal design of taste and flavor: practical collaboration between chef and scientist
}

\author{
Hiroya Kawasaki ${ }^{*}$ and Koji Shimomura ${ }^{2}$
}

\begin{abstract}
Background: Recently, many chefs have collaborated with researchers and used scientific techniques in their cooking. These researchers advise chefs from a scientific perspective. However, they do not know what chefs think and what concept they want to express through their dishes. Once scientists understand what motivates chefs in the creation of their new dishes, they would be able to provide chefs with more precise advice.

Findings: The authors identified culinary success factors (CSFs) from context analysis of a culinary magazine for chefs and visualized the relationships between the CSFs when renowned chefs trained in Japanese and French cuisine create new dishes. The results revealed differences not only in cooking techniques, ingredients, and condiments but also in cognitive structure (pattern of thinking) when creating new dishes. One of the authors (KS) has two Michelin stars for his French restaurant. He believes that umami affects the flavor of the main ingredients, which allows him to feature the intrinsic characteristics of the main ingredients. The chef's cognitive structure is apparent in his cuisine.
\end{abstract}

Conclusions: Based on the results, the chef is advised to understand the nature of umami substances, how to recognize their tastes or flavors, and create a dish that brings flavor changes temporally. In a demonstration, a new dish is unveiled using an umami ingredient according to such a concept, which fits chef's cognitive structure.

Keywords: Chef, Laddering, DEMATEL, Cognitive structure

\section{Findings}

\section{Cognitive structures of top chefs}

Recently, chefs have become interested in what is happening in the pot when they are cooking [1]. Such chefs have collaborated with researchers and used scientific techniques in their cooking. However, researchers are not usually chefs and do not know what chefs think and what concept they want to express through their dishes. The chef's cognitive structure is thought to be apparent in his cuisine. Once scientists understand what motivates chefs in the creation of their new dishes, they would be able to provide chefs with more precise advice.

Klosse et al. [2] conducted interviews and identified six culinary success factors (CSFs) involved in chefs' development of products (dishes): (1) name and presentation befitting expectations, (2) appetizing smell

\footnotetext{
* Correspondence: hiroya_kawasaki@ajinomoto.com

${ }^{1}$ Institute for Innovation, Ajinomoto Co., Inc., 1-1, Suzuki-cho, Kawasaki-ku,

Kawasaki-shi 210-8681, Japan

Full list of author information is available at the end of the article
}

suitable to the food, (3) good balance of flavor compounds in relation to the food, (4) presence of umami, (5) a mix of hard and soft textures apparent in the mouth, and (6) high flavor richness. Although these factors are important in developing new dishes or improving existing ones, the relationships among them are not clear.

We have recently [3] identified the following CSFs from discussions in monthly articles for professional chefs [4] through the laddering technique: (1) utilization of main ingredient texture, (2) utilization of main ingredient flavor, (3) utilization of main ingredient umami, (4) featured main ingredient, (5) good pairings (complements) between main and secondary ingredients, (6) not too rich, (7) good balance, (8) cuisine more Japanese in style, (9) elegance, and (10) surprise (Table 1). Laddering is a potential interviewing technique for exploring cognitive structures [5]. We also investigated the relationships between 
Table 1 Culinary success factors identified by laddering [3]

\begin{tabular}{l}
\hline Factors \\
1. Utilization of main ingredient texture \\
2. Utilization of main ingredient flavor \\
3. Utilization of main ingredient umami \\
4. Featured main ingredient \\
5. Good pairings (complements) between main and secondary \\
6. Not too rich \\
7. Good balance \\
8. Cuisine more Japanese in style \\
9. Elegance \\
10. Surprise \\
\hline
\end{tabular}

The numberings in the table menus were set for visibility.

CSFs in Japanese chefs trained in Japanese or French cuisine by using the Decision-Making Trial and Evaluation Laboratory (DEMATEL) method (Figure 1) [6]. The DEMATEL method consolidates a professional group's knowledge to identify the causal relationships between complicated factors. The comparison of results suggests a difference in type of cuisine affected not only by cooking techniques, ingredients, or condiments but also cognitive structure when creating new dishes.

\section{Cognitive structure-based consultation to chefs}

Cooking techniques have been developed for processing the ingredients cultivated locally. For example, chefs of Japanese cuisine have developed techniques for using Japanese ingredients. Today, however, chefs all over the world are connected to each other [7]. They can therefore use the ingredients and cooking techniques of other countries. For example, chefs of Japanese cuisine can use French ingredients such as foie gras and chefs of French cuisine can use Japanese ingredients such as soy sauce.

The umami taste is one of the basic tastes discovered by Japanese scientists, and umami-containing condiments are common in Japan [8]. Although umami does not constitute a key component in classic French cuisine, contemporary chefs of French and other Western cuisines are interested in and understand the concept of umami [9]. Japanese cuisine uses a lot of umami condiments such as soy sauce and dashi made from shaved dried bonito and/or dried konbu seaweed. Japanese chefs have developed a unique technique called konbu-jime, which means marinating with konbu seaweed. When raw fish is placed between dried konbu seaweed, the water from the fish is absorbed by the konbu seaweed and the umami compounds of the konbu seaweed move to the fish.

One of the authors (KS), who is a prominent chef in Japan, has a two-Michelin-starred French restaurant. When he was told to use the konbu seaweed for his Iberian pork dish, he mentioned that although he would like to utilize the umami taste of the konbu seaweed, the strong flavor of the konbu seaweed would not be in keeping with the style of French cuisine.

One of the authors (HK) administered the DEMATEL questionnaire to the other author (KS) and analyzed his cognitive structure when he created new dishes. The results revealed that the chef believed that umami affected the flavor of the main ingredients, which allowed him to feature the intrinsic characteristics of the main ingredients (Figure 2). This means that umami is not only one of the basic tastes but also has a strong influence on his dish. This is probably why konbu-jime is hard to use for his dish. In fact, as umami (3) influences flavor (2), main ingredient (4), cuisine more French in style (8), and surprise (10) mutually in his cognitive structure, the chef believes that the flavor of the konbu seaweed affects the cuisine more French in style. Thus, in the planning of the Iberian pork konbu-jime dish, he was advised to use the umami of the konbu seaweed but remove the flavor of konbu seaweed while leaving the flavor of the pork.

\section{An example of a dish concerning that utilizes the chef's cognitive structure}

We provide an example recipe created by one of the authors (KS) for the Science of Taste symposium. The

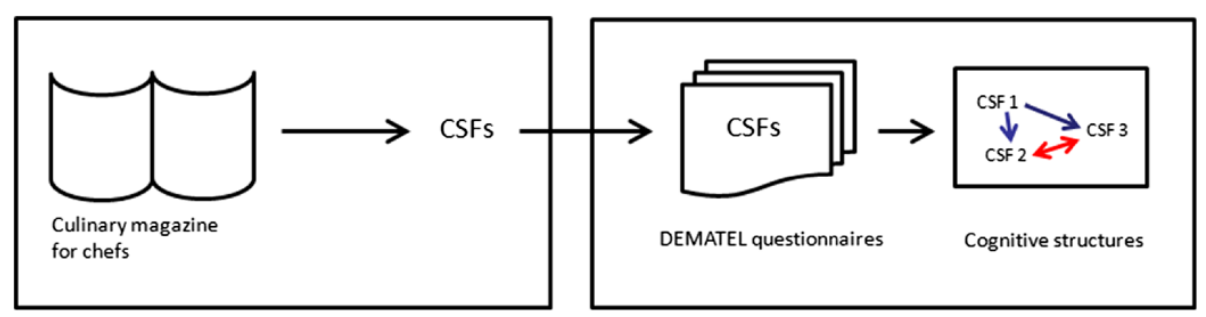

Step 1. Laddering

Step 2. DEMATEL analysis

Figure 1 Scheme for the combination of laddering and DEMATEL method. 


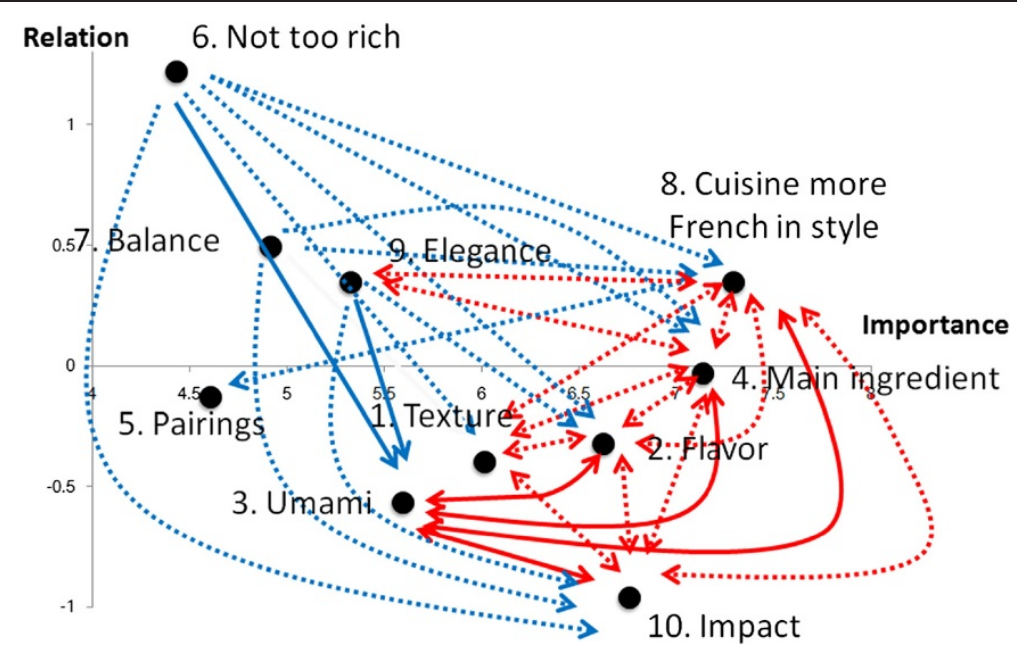

Figure 2 Digraph of chef Koji Shimomura analyzed by the DEMATEL method. The blue arrows are uni-directional, while the red arrows are bi-directional. Solid lines indicate a direct relationship to umami (3), while dotted lines indicate an indirect relationship.

recipe was developed while analyzing the chef's cognitive structure. The photographs of the cooking procedure are shown in Figure 3.

\section{Roasted Iberian pork marinated with dried konbu seaweed} Below are the ingredients of the dish:

$180 \mathrm{~g}$ of Iberian pork pluma (a type of loin)

$25 \mathrm{~g}$ of Rausu konbu

$8 \mathrm{ml}$ of white wine

$10 \mathrm{~g}$ of cherry wood chips

Trim the fat from the Iberian pork pluma. Brush the Rausu konbu with white wine. Heat the konbu in a convection oven at $130^{\circ} \mathrm{C}$ for $2 \mathrm{~h}$ to produce the Maillard reaction and smoke the konbu with cherry wood chips. Marinate only one side of the pork with the konbu for 2 days. Sauté the marinated pork in a frying pan and then slice the meat. Garnish with salted black peppers, pickled small onions, and wine-marinated white grapes, and serve.

The umami taste was added to only one side of the pork. When the meat was chewed, the umami taste was released from one side of the meat while the flavor of the pork was released from the other side. The free glutamate concentration of the konbu-marinated surface of the pork was increased after marinating with konbu (Figure 4). The hypothesis of the temporal heterogeneity

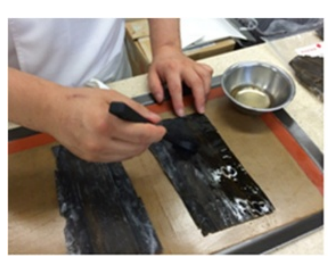

1. Brush the konbu with white wine.

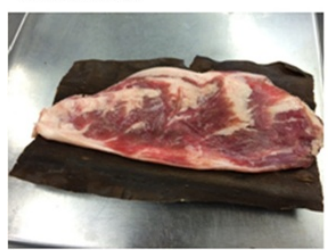

4. Marinate pork on only one side with heated and smoked konbu.

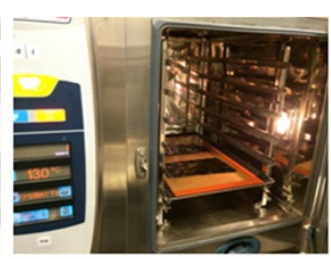

2. Heat in a convection oven at $130^{\circ} \mathrm{C}$ for 2 hours.

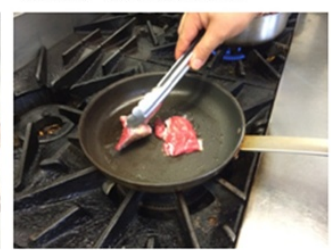

5. Sauté the marinated pork meat.

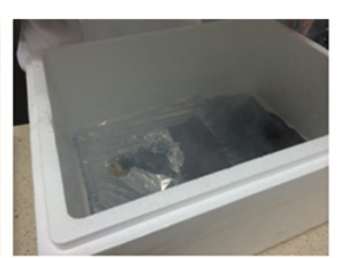

3. Smoke with cherry wood chips.

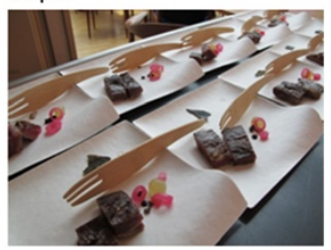

6. Garnish and serve.

Figure 3 Procedure for konbu-marinated lberian pork. 


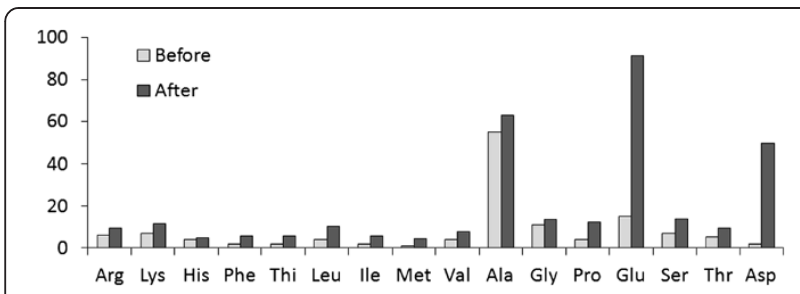

Figure 4 Free amino acid concentration $(\mathrm{mg} / 100 \mathrm{~g})$ of the surface of the pork meat before and after konbu marinating, respectively (analysis by the Umami Information Center).

design of the flavor is shown in Figure 5. We expect that the diner could taste simultaneously the umami and pork flavors but not a strong konbu flavor. Tasting samples were prepared for the audience of the Science of Taste symposium.

\section{Conclusions and future outlook}

We identified the CSFs from discussion articles in culinary magazines and investigated the relationship among the CSFs, i.e., the cognitive structures of the chefs. We found that there are different cognitive structures for different types of cuisines. In addition, we offered cognitive structure-based consultation to the chef when he created the dish of Iberian pork marinated with konbu seaweed. As the advice for the chef's creation was guided by his cognitive structure, he could receive the advice without discomfort.

Chefs consider a number of complex factors arising from their own cognitive structures when they create new dishes for their customers. Their cognitive structures depend on how they were raised, what circumstances they experienced, and what they would like to express through their dishes. If scientists can understand better how chefs think, there would be mutual understanding between scientists and chefs.

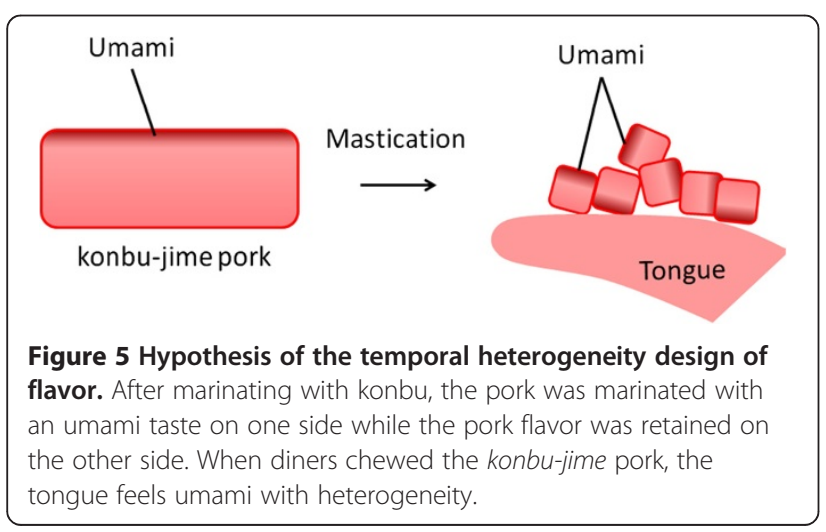

\section{Abbreviations}

CSF: culinary success factor; DEMATEL: Decision-Making Trial and Evaluation Laboratory.

\section{Competing interests}

The authors declare that they have no competing interests.

\section{Authors' contributions}

HK designed the study, conducted the study of laddering and the DEMATEL method, and wrote the manuscript. KS prepared the tasting dishes. Both authors read and approved the final version of the manuscript.

\section{Acknowledgements}

The authors would like to thank Prof. Toshiki Yamaoka from the Department of Design and Information Sciences, Wakayama University, for donating the DEMATEL method analysis software. The authors confirm that they received no external funding for this research.

\section{Author details}

'Institute for Innovation, Ajinomoto Co., Inc., 1-1, Suzuki-cho, Kawasaki-ku, Kawasaki-shi 210-8681, Japan. ${ }^{2} E d i t i o n$ Koji Shimomura, Roppongi T-Cube, 3-1-1 Roppongi, Minato-ku, Tokyo 206-0032, Japan.

Received: 2 December 2014 Accepted: 2 December 2014

Published: 24 February 2015

\section{References}

1. Williams L: Q\&A: the Nordic food lab. Flavour 2012, 1:11.

2. Klosse PR, Riga J, Cramwinckel AB, Saris WHM: The formulation and evaluation of culinary success factors (CSFs) that determine the palatability of food. Food Serv Technol 2004, 4:107-115.

3. Kawasaki H, Kasamatsu C, Nonaka M: Cognitive structures based on culinary success factors in the development of new dishes by Japanese chefs at fine dining restaurants. Flavour 2015, 4:1.

4. Meeting of Shibata Integrated Japanese Culinary Techniques: Challenging Kyoto Cuisine. In Professional Cooking. Edited by Yodono K. Tokyo: Shibata: 2011. 01-2012.07.

5. Reynolds TJ: Laddering theory, method, analysis, and interpretation. J Advert Res 1988, 28:11-31.

6. Shieh J-I, Wu H-H, Huang K-K: A DEMATEL method in identifying key success factors of hospital service quality. Knowledge-Based Syst 2010, 23:277-282

7. The Culinary Institute of America: The report of Worlds of Flavor 2013. [http://www.worldsofflavor.com/archive/2013/overview]

8. Yamaguchi S, Ninomiya K: Umami and food palatability. J Nutr 2000, 130:921S-926S

9. Mouritsen OG, Styrbæk K: Umami: Unlocking the Secrets of the Fifth Taste. New York: Columbia University Press; 2014

doi:10.1186/2044-7248-4-12

Cite this article as: Kawasaki and Shimomura: Temporal design of taste and flavor: practical collaboration between chef and scientist. Flavour 2015 4:12.

\section{Submit your next manuscript to BioMed Central and take full advantage of:}

- Convenient online submission

- Thorough peer review

- No space constraints or color figure charges

- Immediate publication on acceptance

- Inclusion in PubMed, CAS, Scopus and Google Scholar

- Research which is freely available for redistribution 